\title{
Mentor-Managed Design Challenges for First Year Engineering
}

\author{
Carolyn MacGregor, Ph.D \\ Department of Systems Design Engineering, \\ University of Waterloo \\ Waterloo, Ontario CANADA N2L $3 G 1$ \\ cgmacgre@engmail.uwaterloo.ca
}

\author{
Linda Carson, $\mathrm{M}$ \\ Waterloo Unlimited, \\ University of Waterloo \\ Waterloo, Ontario CANADA N2L 361 \\ linda@unlimited.uwaterloo.ca
}

\begin{abstract}
The authors identify the main challenges facing engineering students and instructors during hands-on design projects and give an overview of the mentor-managed approach they take in a first year design course. Key features of the course include mentor management, choosing a design challenge of a suitable scope, providing an appropriate systematic design methodology, and structuring the design project around staged deliverables. They describe, in more detail, two distinctive components of the course: usability testing with modified design walkthroughs, and an introduction to creative practice and design through a Scrapheap Challenge.
\end{abstract}

\section{Introduction}

People who teach design face unique pedagogical challenges. Our students arrive bright and full of enthusiasm but lacking practical skills in design, group work, and applied science. We'd obviously like to expose students to hands-on design activities as soon as possible, but how? Can we teach design in practice? Can we convey the realities of collaborating with a design team to establish requirements, deal with constraints, implement solutions, and then to test and validate these realized designs? Can we also sustain the enthusiasm of the students for effective innovation while they're still developing the technical foundation they'll need to fulfil the demands of their imaginations?

Some engineering schools delay the introduction of open-ended design projects until the student is in the second, third, or even final year of the engineering program. The commonly accepted rationale for this approach is that it allows the students to master enough basic applied science to be able to derive reasonable engineering solutions. It also avoids three substantial pitfalls of first year design education:

1. Teaching design to first year students is difficult;

2. Managing an open-ended design project demands extraordinary teaching support and timeconsuming marking; and

3. Students in the midst of the design process can be confused, frustrated, and emotional. Emotional students give emotional teaching evaluations.
Teaching isn't a popularity contest, but there's no denying the impact of evaluations on instructors and departments.

However, most students actually look forward to design opportunities. They enter engineering with the goal of building and developing things, such as devices, software, structures, and systems. They arrive well-motivated - if not well-prepared - to start designing. If we can harness that energy early, we can offer students several design projects throughout their undergraduate careers. It may be difficult, and it definitely takes more work and more support than a conventional lecture or seminar. (Also, it's a mistake to ask for teaching evaluations during the highfrustration stages of the course. Seasoned instructors will ask for teaching evaluations on design courses only after the projects are complete. Invite student feedback when they've had a chance to reflect on what they've learned and accomplished.)

For the past 35 years, the Department of Systems Design Engineering at the University of Waterloo has made hands-on design projects part of its first year curriculum. Our view is that such exposure gives students a greater appreciation for the applied science courses that will follow. In this paper we'll discuss how, in the department's flagship first year course, our students undertake a substantive hands-on design challenge in their very first term . . . and thrive. This course is carefully shaped and delivered to make the most of our students' strengths and enthusiasm, while 
offering them meaningful support in the areas where they're under-prepared. We'll describe what we think we're doing right, what we're still working on, and what the students get out of it.

\section{What's so hard about teaching design?}

Teaching the theory, art, and practical approaches to engineering design poses special challenges. We need to provide enough structure and practical methodology to equip students to proceed systematically. At the same time, we need to avoid swamping students with analysis at levels of detail that preclude innovation and creativity. We need to devise meaningful design problems with enough scope for students to experience the design cycle. A complex problem outside the students' experience will confound them. A trivial problem doesn't challenge them, or reinforce the usefulness of the design process. These problems must be open-ended but do-able. Do solutions exist that are within the students' technical abilities to implement and test? Can students take their solutions to the level of functional prototypes in a reasonable time frame? (At UW, for example, an academic term lasts just 12 weeks.) Meanwhile, we still face the primary challenge as instructors: providing timely guidance and constructive feedback on the student's design process and outcome.

\section{What's so hard about studying design?}

"Engineering has many dimensions, but the idea of failure spreads across all of them.”

Henry Petroski[1]

Many engineering students facing their first design project are excited by the opportunity to be creative and innovative. At the same time they're terrified by the prospects of failing, on many levels.

First, it's a lot of work, and it's a lot of group work. Some students will stumble over the time management and teamwork challenges. Others will falter with the realization that design is not a spectator sport. They can't earn top marks sitting quietly in the back row taking notes. They have to participate, contribute, and perhaps make public mistakes. They'll have to try out ideas aloud, in front of their team (if not the entire class).

Perhaps the most critical skills gap is their inexperience with the sorts of open-ended assignments that typify design practice. The high performing students are sometimes the worst prepared for design because, in general, their academic success in high school has been measured against closed problems. A closed problem is any question or challenge for which there's a clear known answer, an obvious target. What's the integral of $7 x^{3}+10 x^{2}-3$ ? Calculus is tough, but there's always a right answer. Design is considerably more lifelike than that. Here we typically face open problems for which there may be a thousand solutions, or none.

\section{Seven characteristic problems with student design projects}

Our job as educators is to provide an appropriate framework that encourages creativity and immerses the students in the realities of engineering design. Over the past four years, we have developed a mentormanaged approach for teaching engineering design to first year students. This approach is largely intended to foster a creative, effective design process, and to counter or avoid the most common problems with student design projects. In our experience, these problems are:

1. The belief that Design is just common sense, right? Of course, there's nothing common about sense, or good design. However, we always meet some students who believe it's so straightforward that they don't need a course, a method, or practice. Many of the same students accept as a corollary that Creativity is divinely inspired. There's no point, it would seem, in working on your design until you are struck by the perfect idea.

2. Jumping to solutions: Students are tempted to skip the design process and rush straight into implementing the first idea that looks like a solution.

3. Impractical solutions: Student designs may sound good in principle and look good on paper, but are they feasible? Affordable? Useable?

4. Design by procrastination: The last-minute design solution usually satisfies at most one criterion . . . the deadline.

5. Designing for an $N$ of 1 : Picture the student as the ultimate, and only, prospective user.

6. There is no $I$ in TEAM. Students may acknowledge the potential in teamwork but they still need skills and guidelines for how to make those teams effective.

7. And, of course, fear of the open problem.

\section{A hands-on first year design project}

"Creativity requires faith in the knowledge that you have the right to proceed even when you don't know exactly what you're doing."

Twyla Tharp[2] 
Our flagship course is the Introduction to Systems Design Engineering, a one-term double course. The students spend four hours of class time a week on engineering graphics and technical communication, including CAD modelling. They spend another four hours of class time each week on learning the basics of engineering as a profession, engineering design, and related topics such as risk management, optimization, and health and safety. Finally, the students take on a hands-on design project. The instructor divides the class into teams of 5-6 students each and presents them with a project theme. Over a 10-week period the teams are expected to work outside class time to design something that satisfies the challenge, including producing a functional prototype. At the end of the term, the design teams present their design solutions and prototypes in science fair fashion.

\section{Setting an appropriate design challenge}

For example, the design challenge presented to our students in the fall of 2003 came on the heels of the major blackout experienced by much of Eastern Canada and the USA during August of that year. The challenge was worded: "Design a physical device, or a device with a physical component, to assist Canadian students with an everyday task during a blackout." The scope is intentionally broad. The students must refine the problem into a manageable task by identifying the component they wish to address.

The challenge has to present a non-trivial problem whose scope is appropriate to the time available. (Our students have ten weeks.) The challenge has to admit solutions that are feasible on a limited budget. (Each team has a budget of forty dollars to complete their entire project, including photocopying and posterboard presentation.) Finally, the challenge must be relevant to the students' own experience; if they can't be technical experts, let's assign a problem area in which they are reasonably well-informed.

We require students to build on their existing background knowledge, and we stress the importance of information literacy and patent searches. To avoid reinventing the wheel, students must take responsibility for reading widely in the area and seeking out existing technical solutions. We usually field sixteen design teams in the first year class. This year, most of them narrowed the scope of the problem to cooking, lighting, or refrigeration without electricity. One team produced a genuinely novel product design that may well be patentable.

\section{A scaleable design methodology}

To provide an appropriate working framework, we introduce the students to a modified user-centred (UCD) spiral design process at the beginning of the term. The UCD spiral design process (loosely adapted from Boehm's Spiral Model for Software [3]) is a basic iterative design approach incorporating cycles of analysis, design, implementation, and testing and validation (See Figure 1). This approach is both accessible and scaleable [4]. Students can grasp it in first year, and use it with increasing sophistication in their senior classes. The UCD spiral design process reinforces the need for students to ground their design in terms of specific tasks and users (not just the " $\mathrm{N}$ of 1 "). At the same time, the process reinforces the iterative testing of a series of prototypes escalating in fidelity and functionality. We have found that this approach encourages the student to consider design from a functional and practical perspective. It also dispels the popular misconception that we must envision the perfect, complete design before we begin to create and test.

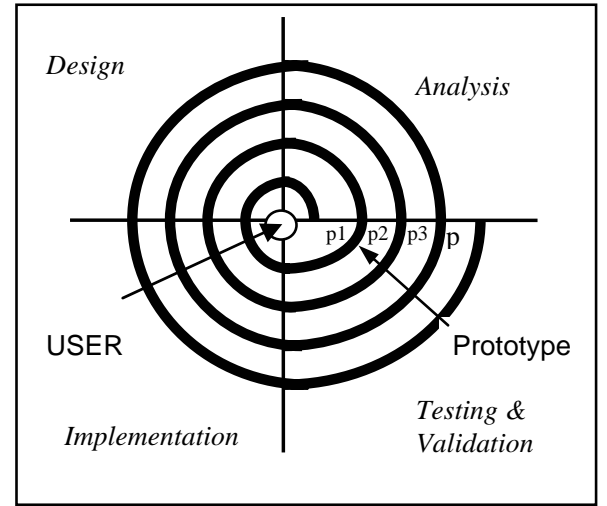

Figure 1. UCD spiral design method

\section{Who's driving?}

We are all familiar with how, in a traditional classroom setting, the instructor sets assignments and, after they're delivered, evaluates them. In a similarly instructor-driven design project, the instructor would set the requirements in terms of design problems, acceptable solutions, deliverables, and due dates. The instructor's interaction with the students would likely be limited to questions in class and feedback after the projects had been submitted for grading.

Senior design projects may be student-driven instead. The students select a design project of interest and work with a supervisor to establish acceptable 
deliverables. The student must take the lead in seeking advice from the supervisor.

In Introduction to Systems Design Engineering, however, we have recently adopted a mentor-managed approach. Students choose design projects - within a context established by the instructor-and bring to them all the enthusiasm and motivation commonly associated with student-driven projects. Meanwhile, the mentors - the instructor and teaching assistantsguide the students through a structured design experience intended to offer them the opportunity to try, and the safety to stumble.

The instructor bears the primary teaching responsibility and sets the design challenge. The teaching assistants serve as project managers for four different teams of students. The teaching assistants have weekly meetings with their respective student teams. The instructor, in turn, has weekly meetings with the teaching assistants. The instructor teaches design concepts and methods, from task analysis and prototyping through optimization and engineering safety. The project managers reinforce course concepts, monitor group dynamics and track project progress. The teaching assistants can keep tabs on whether the students are actually applying the concepts and methods to their design projects.

Instructor contact with the students throughout a mentor-managed design project is high, and the experience is structured to enforce good work habits, teamwork, and design process. While the mentormanaged approach has increased the number of deliverables and related workload for the students (and the instructor), it provides greater payback in terms of learning and overall satisfaction with the course.

\section{Staged deliverables}

To help students avoid "design by procrastination," we have developed a series of activities and deliverables that are presented in-class throughout the term. The main activities include: the creation of design teams and the setting of team charters; a lecture on idea generation techniques coupled with an in-class scrapheap challenge; a workshop on information literacy and patent searches; and a series of in-class design walkthroughs with usertesting. The deliverables for the project are due in stages and include a design proposal, at least three prototypes (ranging from low-fidelity to functional, demonstrating evolution of design), and a final technical report with design specifications and appropriate engineering drawings. In addition, each student keeps a design logbook which is evaluated throughout the term. The staging of deliverables suggests (and enforces) a reasonable timetable for design development, and ensures that no one lags far behind unnoticed. This gives the instructor and teaching assistants opportunities to redirect design teams that have veered off-track, or stalled completely.

\section{Design walkthroughs}

One key to our mentor-managed approach is that the very shape of the design project is intended to provide structure and support appropriate for first year students.

Novice designers may naively underestimate the amount of time involved in a full design process. This is particularly true for students who assume that design is about finding that one right answer and that if they just leave it long enough they will have an inspiration at the eleventh hour. Experienced designers know they face a long, creative, but sometimes arduous process. Design isn't magic, and it involves a methodical approach.

When students leave projects to the last minute they have a negative impact, not only on themselves, but also on the instructor. It becomes next to impossible to give timely feedback during the design process, feedback that might help improve the final deliverables and/or the design experience. (Furthermore, the instructor is almost certain to hear from irate colleagues who see student performance plummet in their courses as the design project spins out of control.)

Rather than flinging first years into the deep end-with a massive project and one end-of-term deadline-we ask the teams to meet several interim deadlines with significant deliverables. The most valuable of these mid-project deliverables are the design walkthroughs.

\section{Systematic review and user testing}

"The best path to innovation is through what we call enlightened trial-and-error. The day starts, make a bunch of crummy prototypes and the next day show them to customers, users and manufacturing. They'll tell you what's wrong. Take copious notes and fix it."

David M. Kelley[5]

The design walkthrough is a common assessment method used by usability professionals [6]. The basic method involves asking a typical user to try to accomplish a set of tasks with the product under design. This method fits in nicely with the UCD Spiral Method. It helps to build a framework for the testing and validation of the prototype at the end of each cycle through the spiral. The designer observes the product 
in use and identifies points of user confusion and prototype failure.

Design walkthroughs can be adapted for use at any stage in the design process. In the conceptual development stage, design walkthroughs can be done with low-fidelity prototypes such as paper-and-pencil renderings and paper mock-ups with sticky notes. This allows the designer to test out ideas before investing a large amount of time in making the prototypes. For students, this is ideal. Low-fidelity prototyping also encourages them to be flexible in their commitment to a particular design strategy. As the design progresses, they test successively higher levels of functional prototypes. The students move from testing design concepts to actually conducting performance testing and comparing their results to derived benchmarks set as part of the design process.

The level of interaction between the designer and the user varies depending on where one is in the design process. In the early stages of design, we encourage a high level of interaction. The user may need to imagine the functionality of the product, or aspects of the product, and a design walkthrough encourages dialogue about the design from functional as well as aesthetic perspective. As the design progresses and the level of testing becomes more sophisticated, there is less interaction between the user and the test monitor or designer. This helps students to focus on objective measures for testing and validating the design, and encourages them to evaluate their design against the requirements established at the outset. Notice that we set an overall design challenge whose potential target population could include user groups similar to the student designers. This lends validity to doing the initial walkthroughs with their classmates as test users.

\section{Key benefits to design walkthroughs in the classroom}

The three planned design walkthroughs are important teaching tools. Preparing for walkthroughs means students are obliged to:

1. Use the UCD spiral design method (rather than leap to solutions).

2. Conform to a reasonable timeline for development.

3. Expect and accept feedback, especially from the user's perspective.

Students tend to respond to in-class deadlines and presentations to peers. However, they often feel that their solutions must be "finished" before they can be shown. We've all seen the result: remarkable displays of presentation slides and hand-waving at the expense of an honest representation of where the design is to date, including the limitations. The design walkthrough is an effective technique for enforcing inclass deadlines while minimizing fear of failure. As a result, we see less showmanship and more designership.

The design walkthrough focuses on users, usability and function. Nothing cures a student of "designing for an $\mathrm{N}$ of 1 " like facing test users across a prototype and seeing how they expect the device to work.

\section{Adapting the design walkthrough for students}

We have adapted the design walkthrough method for use with our first-year engineering design projects. Students are taught about testing and validation, and are introduced to design walkthroughs as a basic method of design evaluation. During that lecture, students are introduced to the role of test monitors (who lead the testing sessions and record observations), verbal(think aloud) protocols (where users try to perform the assigned task and talk the tester through their thought processes at the same time), Wizard of $\mathrm{Oz}$ simulations (where the designers simulate the functionality of the design for the user), and paired evaluations (by two users who talk with each other about the design) [6,7]. Paired evaluations are a response to the common problem of a single user feeling uncomfortable talking aloud about a design to designers. This can be especially obvious amongst peers in a classroom setting. Paired evaluations are less stressful for the user, and often more revealing for the designer [6].

\section{Walkthrough \#1: Concept sketches and 3D models}

The first session is a design walkthrough of the concept sketches and 3D models the teams created for their proposals. Each team assigns two of its team members to be test users for other groups. The remaining team members take on the roles of test monitor, functionality simulators, and recorders of observations. With some careful scheduling (see Table 1) they can accomplish two rounds of testing in a fiftyminute class. The time for activities is purposely kept very short. The sense of urgency keeps students focused on the tasks, and the quick pace gives every team the benefit of testing with more than one set of 
users. Invariably the second pair finds other things that the first did not.

Table 1. First design walkthrough

\begin{tabular}{|l|r|}
\hline \multicolumn{1}{|c|}{ Activity } & \multicolumn{1}{c|}{ Time } \\
\hline $\begin{array}{l}\text { Instructions \& set-up time: Teams } \\
\text { make sure that their prototype is } \\
\text { ready and that the roles of each } \\
\text { team member are understood. }\end{array}$ & 10 minutes \\
\hline Paired Evaluations, round \# 1 & 5 minutes \\
\hline Team Debriefing and Redesign & 10 minutes \\
\hline $\begin{array}{l}\text { Paired Evaluations, round \# 2 (with } \\
\text { a different pair of users) }\end{array}$ & 5 minutes \\
\hline Team Debriefing & 5 minutes \\
\hline Class Debriefing & 15 minutes \\
\hline TOTAL TIME & $\mathbf{5 0}$ minutes \\
\hline
\end{tabular}

Class debriefing is essential. The students need to explicitly reflect on the design walkthrough method. What did they learn about their own designs? What might they do differently for the next scheduled walkthrough? Invariably, the students learn that their designs are not as easy-to-use as they believed them to be. They also learn that the feedback provided by other students can be meaningful. In our experience, students are more willing to accept peer feedback in the timely, non-competitive context of a design walkthrough than in the retrospective critiques given after formal presentations. They also learn how to give meaningful feedback to others from a task-based perspective, something more on point than "I don't like the colour."

In-class design walkthroughs are non-competitive but motivational. Students see the flaws of their own designs and see how their team's solution to the design problem compares to the solutions of other groups. This generally propels students to set a higher standard for themselves in the next walkthrough.

To encourage this sort of reflection, we required each individual student to write their own summary of the design walkthrough experience. They report their findings about their design and their recommendations for the next design walkthrough, both in terms of modifications to the product design and modification to the design walkthrough method used by the group.

\section{Walkthrough \#2: Higher fidelity prototypes}

Roughly two weeks later, the students bring their latest prototypes to class for another design walkthrough with classmates as test users. At this point, the students usually switch roles so that everyone takes a turn as a user for another team and as a test monitor for their own design. By this time, the design is taking on a higher level of fidelity so that critical functions can be tested.

\section{Walkthrough \#3: Senior students as test users}

The third design walkthrough session is scheduled for the week before the final designs are due. Upper year students are invited to be the users. Knowing that upper year students will be part of the design walkthroughs encourages the first year engineering students to get the projects as close to completion as possible. From an instructor's perspective, this is another strategy to keep teams on track without nagging.

The third walkthrough is a good opportunity for the senior students, teaching assistants and the instructors-mentors one and all-to give constructive feedback while there's still time for modifications.

\section{Design presentations are the ultimate walkthrough}

The final design presentations are done in a science fair format, with engineering faculty, staff, and graduate students serving as evaluators. Each team prepares a three minute overview and a posterboard to describe their design process. Teams are required to have all three (or more) of their prototypes available so that evaluators can see how the design has evolved from concept to functional prototype. Functional prototypes must be working for the presentations.

We emphasize team learning throughout the course. All team members need to be able to answer any questions pertaining to any aspect of the design. This prevents team members working so independently on sub-components of the design that they never share knowledge and skills.

Each student is responsible for conducting a peer evaluation on an another (assigned) team. We have found that by the end of the course, after participating in three rounds of designer walkthroughs, the students are well prepared to ask insightful questions of their peers about the design process.

\section{The Scrapheap Challenge}

Taking a mentor-managed approach also means teaching students to walk before they can run. Early in the term, we schedule a pair of classes back-to-back: the creativity seminar, and the Scrapheap Challenge. They provide students with some theory and practice in idea generation, followed by a low-stakes, highenergy design assignment to break the ice in their newly-assigned teams. They also offer our readers a 
snapshot which serves as a surprisingly faithful portrait of the overall course. We begin, as in the course, with theories, models, and context. We suggest a methodology, have them practice, and offer feedback. Then teams tackle a (playful) design challenge. They produce working prototypes to a deadline, and test them-often to failure. The bonus is that we laugh, a lot.

\section{Design students and creativity, a love/hate relationship}

Many students share the common misperception that creativity is like lightning, a chance thing that strikes from above. The reality is that lightning arises from special circumstances, and there are plenty of things you can do to bring it upon yourself. Just as golfing in a thundershower increases your odds of being struck, a systematic creative process increases your odds of being inspired. For many of these high performance students, this is the riskiest part of the course. They can write an essay or ace an exam. They're much less secure trying to "blue-sky" ideas in a completely open problem area. Early in the term, we teach the students some practical skills for generating ideas, both as solo designers and as team players.

\section{Creative practice}

How to catch a big fish:

1. Catch a lot of fish.

2. Throw back all the little ones.

\section{Linda Carson}

Many students don't realize that psychologists study creativity every bit as deeply as engineers study thermodynamics. In the first part of the creativity seminar, we introduce them to some of the fundamental models that have arisen in creativity research. For example, Graham Wallas describes idea generation in four stages[8]:

1. Preparation, where we immerse ourselves in information about the problem area;

2. Incubation, where we attend to other concerns while ideas grow beneath the level of consciousness;

3. Illumination, where we experience the Aha! moment of a new idea;

4. Verification, where we examine the idea thoroughly to see if it's valid, relevant, complete.

This model offers critical insights for student designers. It proposes that we can't just wait for ideas, we must prepare for them, equipping ourselves with all manner of information that might contribute. We must also examine the quality of the ideas after they arrive.

In class, we identify and give examples of closed and open problems. We distinguish between convergent and divergent thinking, and when each might be useful, particularly at different stages of the design process. The students learn about personal qualities that promote creative practice, such as a tolerance for ambiguity and a sense of humour. They learn about thinking skills that contribute to idea generation, such as pattern detection and forced associations. We practice word association games in class as illustrations, and warm-ups.

\section{Becoming a think tank}

Of course, it's not enough to know how to generate ideas oneself. Students also need to know how to work effectively with other members of the design team. Before they embark on even the smallest design challenge, we give them tips on how to generate ideas as a team.

1. Start solo. Generate some ideas to bounce off the other team members.

2. Defer judgment on your ideas and give yourselves the freedom to fail.

3. Seek quantity, not quality, of ideas. Look for the second right answer.

4. Question assumptions. What rules can we break?

5. Take ideas over the top. You can't tell where the limit is until you've crossed it.

6. Follow-through: combine and extend ideas; use them as stepping stones to new ideas.

7. Take notes. A meeting where no one takes notes, never happened.

\section{Test-driving a variety of idea generation techniques}

In the second part of the creativity seminar, the students practice idea generation techniques in small groups. Each group picks up an envelope containing a short description of a popular idea generation technique (such as mind-mapping, problem reversal, or forced analogies), a problem area, and any special tools they might need. The goal of the exercise is for them to apply the technique to the problem area and generate as many ideas as possible.

These groups are not the same as the design teams. In fact, we ask students to rearrange themselves in the room so that each design team is widely scattered. This gives each design team some familiarity and 
experience with several different idea generation techniques.

The most important thing to stress is that during idea generation the top priority is quantity, not quality, of ideas. We're trying to catch a lot of fish. There's plenty of time later to weigh them.

For example, a group might be assigned to use bibliomancy (selecting random phrases from a book) to generate answers to the problem How can we make visiting the dentist more attractive? They'd pick up a copy of Shakespeare's Complete Works, open it at random, and pick out, perhaps, "Now is the winter of our discontent made glorious summer by this son of York."[9] When they look for associations between that and the dentist's office, they might propose sun lamps in the treatment area so patients can tan during their root canal.

At the end of the exercise, each group appoints a spokesperson to give a sixty-second synopsis: What was the problem area? Roughly how many ideas did they generate? What was their favourite idea-not necessarily the best idea, but something fun, inspiring, unexpected?

The instructor takes some time at the end to reflect with the students on how, having generated a wild variety of ideas, they can weigh them against the criteria of their design problem to select "the biggest fish.”

\section{The Scrapheap Challenge}

The Scrapheap Challenge is a ninety-minute design challenge, inspired by the educational British television show of the same name. (The American version is called Junkyard Wars.) Students take on a design challenge, to be solved in a limited time from "scrapheap" components.

What can you do in ninety minutes? Plenty, if the students are prompt. We award bonus points for teams who have their full complement at the start of class. The instructor reminds them of the lessons of the creativity clinic, especially the guidelines on how to generate ideas in a group. The instructor also recaps the UCD design spiral method. Then they're issued a small tool kit, including knives and masking tape, rulers and rubber bands, scissors and string. They're given access to a small heap of scrap (typically an assortment of household recyclables such as cardboard tubes, plastic tubs, and disposable chopsticks), and assigned the Scrapheap Challenge.

For one Scrapheap Challenge, each team had to deliver a shipwreck survivor safely to a desert island as many times as possible in a minute. The desert island was a plastic cereal bowl, complete with sand and a pipe cleaner palm tree, sitting in an empty wading pool. The launch point was a desk on the opposite side of the classroom. Teams earned top marks for survivors making landfall, part marks for getting survivors into the pool, and no marks at all if their survivor hit one of the pipe cleaner "sharks" swimming around the island. The survivors were golfball sized Muppet Baby ${ }^{\mathrm{TM}}$ collectable toys from McDonalds ${ }^{\mathrm{TM}}$.

Annual design challenges in other courses had grown less and less effective. Savvy incoming students researched the "right answers" ahead of time by interviewing their predecessors. So our Scrapheap Challenge changes every year. We've launched golf balls for distance, and raced golf-ball laden boats across the fountain in the Engineering quadrangle. The most important qualities of the Scrapheap Challenge are solvability, multiplicity, and playfulness. We want a challenge that's doable. We want a challenge that admits many different solutions, even under the extraordinary limitations of the assignment. We also want a challenge that will motivate the students, break the ice, and demonstrate that design, at its best, is fun. This playful atmosphere helps to create a safe zone where students take chances, and reward each other with laughter and applause. Table 2 presents the schedule for a typical Scrapheap Challenge.

Table 2. Scrapheap Challenge schedule

\begin{tabular}{|l|r|}
\hline \multicolumn{1}{|c|}{ Activity } & Time \\
\hline $\begin{array}{l}\text { Instructions \& set-up time: Bonus } \\
\text { points are awarded to teams with }\end{array}$ & 5 minutes \\
all members in attendance by 8:15 \\
am - for an 8:30 am class start.
\end{tabular}




\section{Classic design mistakes from the Scrapheap Challenge}

The chief benefit of the Scrapheap Challenge is that it's such a low-stakes assignment that the students have almost no fear of failure. They launch themselves into the project enthusiastically, cheer their classmates loudly, and shriek with despair when an errant Muppet Baby ${ }^{\mathrm{TM}}$ is eaten by sharks. They never stop to think, How does this make me look? or What if I get this wrong? The best thing about the Scrapheap Challenge is that the students make mistakes.

Every year we see students make mistakes, mistakes that drive home the importance of a systematic design methodology more vividly than any lecture might. In fact, we see some of the same mistakes repeated year after year. Here are some of the classics:

1. They don't read the brief fully. What do you mean, we've only got a minute to set up?

2. They start building before they've got a plan. Sometimes that costs them dearly-what if that was the only egg carton in the scrapheap?

3. They don't ask questions. We're not the only design "clients" they'll meet who fail to cover every eventuality in the original brief.

4. They don't coordinate with team-mates. You're building a catapult? But I'm nearly finished the cable car!

5. They don't test. The classroom where the course meets is across the hall from the room where the Challenge plays out. A truly remarkable number of students get so comfortable at their desks that they never even reconnoitre the test site.

6. Most entertaining of all: they invent rules beyond the brief, and never question them. But we're not allowed to trade materials with other teams. Says who? But that's cheating!

These are good mistakes, educational mistakes, mistakes we'd much rather see during the Scrapheap Challenge than during final design presentations. These are the sorts of mistakes that motivate the entire design process. We bring these mistakes to the attention of all the students during a short, upbeat debriefing at the end of the class. In our experience, they usually laugh. There aren't many times in an instructor's career when you'll see high performance students take themselves and their mistakes so lightly. At the same time, they're not likely to make the same mistakes again.

Students take home the message that creativity is learnable, and that there's plenty of work to be done preparing for and implementing a good idea. They get a hands-on sense of the importance of requirements, constraints, and testing. The week of the Scrapheap
Challenge is especially effective in creating a positive atmosphere that reduces students' fear of failure and introduces them to the excitement of design.

\section{Conclusions}

Teaching design with hands-on projects is demanding at the best of times. Teaching it in first year can be frustrating and time-consuming. If the students lack the technical foundation to match their creative ambition, does a hands-on design project even have any educational value? Our experience at the Department of Systems Design Engineering at the University of Waterloo suggests that the benefits outweigh the considerable challenges.

\section{What goes right?}

The academic content of the first year design course provides conceptual tools, models, and context for the practice of design. The design project proceeds in parallel. Qualities we think are central to its success are:

1. A hands-on design challenge that exposes the students to the complete design process, including user testing and functional prototypes,

2. A mentor-managed approach (rather than an instructor-driven or student-driven project),

3. Assigning a design challenge of a suitable scope: broad enough to encompass a wide range of manageable problems, but admitting a variety of possible solutions within the technical skills, budget, and time available to the students,

4. The use of a suitable design methodology that's accessible to first year students and will scale up as the students gain experience,

5. Staged deliverables, and

6. Fun. Why should students have to wait until their senior year to learn what we all know? Design is exhilarating. Creativity is fun.

Taking a fairly high-contact approach can be rewarding for the students and the instructors. They share their enthusiasm for design, in practice rather than hypothetically. Mentor-managed projects give the students a chance to practise hands-on design, with a safety net.

The design walkthrough is especially useful and might be profitably adapted for other disciplines. This is not to suggest that all disciplines need user testing. However, the walkthroughs create checkpoints throughout the project-interim deadlines-that ensure progress, and create a reciprocal context for peer feedback that is meaningful but non-combative. 


\section{What goes wrong?}

There are always going to be problems with a course that is, in many ways, as open-ended as the design problem itself. The mentor-managed approach demands a great deal of meaningful contact time with students, and design projects are always going to require thoughtful and time-consuming evaluations. But there are other potentially-manageable problems we still hope to be able to address.

The recent experience of first year students is high school, and they tend in this first term to set their standards at the level rather than at an undergraduate level. Can we use carefully-chosen examples of previous student work to raise the standards of originality and reporting, or will this just reinforce students' tendency to seek the single "right answer?" Would that raise the bar or install a ceiling on performance?

We're still struggling to provide as much timely feedback as the students need and deserve. We're investigating the usefulness of online tools for collaboration and project management, as described briefly in another conference paper (see MacGregor, Talukdar, Bains, Jo \& Thomas).

We're not convinced every design team is getting the best from all their participants. How can we level the playing field between, for example, extroverts and introverts in design groups?

This course covers a staggering array of topics, from engineering safety to the psychology of creativity, from professionalism to user testing. When we succeed in systematizing design for our first year students, we pay a price. They learn to break the design process down into meaningful sub-tasks and skills. But they usually lose, for the moment, the important understanding that design is continuous, not discrete. Design is cyclical, not linear. Design is vast and complex and messy, beyond condensing into a single diagram, no matter how many colours and animations we add.

Through comments on course evaluations, we know that some students struggle with what they interpret as "vague" methods and concepts. They request clear formula-type steps for design so that they are guaranteed to always get a 'right answer'. We're still working on ways to incorporate more reflection and synthesis tasks into the project. We want to give the students more chances to pull together the variety of knowledge, skills and techniques the course offers and build a sophisticated understanding of design.

Finally, we're interested in quantifying our observations. Through reviews of student project reporting and video recordings we hope to develop a more quantitative analysis of the improvements in student work over the last four years.

\section{What do students take away?}

A hands-on design project gives first year students a chance to start doing what they came to engineering school to do: design things! It's never too soon, our experience has shown, to counter their misconceptions about creative practice and give them a workable, systematic approach to design. Experiencing the realities of the design process firsthand gives our students a much clearer understanding of the role their applied science curriculum will play in equipping them for the even more challenging design projects that lie in their academic future, and their professional careers.

The design project is a great way to learn the concepts and have fun too!

- 1A Systems Design Engineering Student (2003)

Some times the lessons learned through the first year design project and course are not appreciated by students until well after the course is over. As educators, it is rewarding to receive support for our approach in the way of a message from a sutdent who has moved on to a work term or higher academic term.

The co-op experience has been great so far. Of all the courses in 1A, the 161 course has had the most content I could apply to my work term. Thanks.

- 1A Systems Design Engineering (2004)

\section{References}

[1] H. Petroski, Invention by Design: How Engineers Get from Thought to Thing, Harvard University Press, 1996. [2] J. Rosenfeld, “Here's an Idea!”, Fast Company, April 2000, p. 97.

[3] B. W. Boehm, “A spiral model of software development and enhancement”, IEEE Computer, 1988, 21(5), pp. 61-72.

[4] C.G. MacGregor, "Introducing interactive systems design into a programming course for first year engineers" Proceedings of the HKK Conference, June 13-16, 1999, Waterloo, Ont, pp 173 - 178.

[5] J. Woods, Quotable Executive, McGraw-Hill, Toronto, 2000.

[6] J. Preece, Y. Rogers and H. Sharp. Interaction Design, New York: John Wiley \& Sons, 2002.

[7] T. D. Erickson and H. A. Simon, Protocol Analysis: Verbal Reports as Data, Cambridge MA: The MIT Press, 1985.

[8] G. Wallas, "Stages in the Creative Process," The Art of Thought, n.p.: Harcourt Brace Jovanovich, Inc., 1926; rpt. The Creativity Question. Ed. Albert Rothenberg and Carl R. Hausman. North Carolina: Duke University Press, 1976. 69-73.

[9] Richard III 